Article

\title{
Analysis of Spatial Heterogeneity and Influencing Factors of Ecological Environment Quality in China's North-South Transitional Zone
}

\author{
Haoran Yin, Chaonan Chen, Qingdong Dong, Pingping Zhang, Quantong Chen and Lianqi Zhu *
}

Citation: Yin, H.; Chen, C.; Dong, Q.; Zhang, P.; Chen, Q.; Zhu, L. Analysis of Spatial Heterogeneity and Influencing Factors of Ecological Environment Quality in China's North-South Transitional Zone. Int. J. Environ. Res. Public Health 2022, 19, 2236. https://doi.org/10.3390/ ijerph19042236

Academic Editors: Roberto Alonso González Lezcano, Francesco Nocera and Rosa Giuseppina Caponetto

Received: 5 December 2021

Accepted: 3 February 2022

Published: 16 February 2022

Publisher's Note: MDPI stays neutral with regard to jurisdictional claims in published maps and institutional affiliations.

Copyright: (C) 2022 by the authors. Licensee MDPI, Basel, Switzerland. This article is an open access article distributed under the terms and conditions of the Creative Commons Attribution (CC BY) license (https:// creativecommons.org/licenses/by/ $4.0 /)$
College of Geography and Environmental Science, Henan University, Kaifeng 475004, China; yjsyhr@163.com (H.Y.); 15736870141@163.com (C.C.); dongqd961103@126.com (Q.D.); zhangpp@henu.edu.cn (P.Z.); a13804817736@126.com (Q.C.)

* Correspondence: lqzhu@henu.edu.cn

Abstract: The ecological environment is important for the natural disaster prevention of human society. The monitoring of ecological environment quality has far-reaching practical significance for the functional construction of ecosystem services and policy coordination. Based on Landsat 8 operational land image (OLI)/thermal infrared sensor (TIRS) remote sensing image data, this study selected the normalized vegetation (NDVI), tasseled cap transformation humidity (WI), bare soil (SI), construction index (NDSI), and land surface temperature (LST) indexes from the aspects of greenness, humidity, dryness, and heat. Using spatial principal component analysis (SPCA) and the remote sensing ecological index (RSEI) analyzed the spatial differentiation characteristics and influencing factors of the original remote sensing ecological index $\left(\mathrm{RSEI}_{0}\right)$. The results showed that: (1) the overall RSEI average value of the Qinling-Daba Mountains in 2017 was 0.61, and the ecological environment quality was at a "Good" level. Greenness contributed the most to the comprehensive index of the area, and vegetation distribution had a significant impact on the ecological environment quality of the study area. Heat is a secondary impact, and it has an inhibitory effect on habitat quality; (2) the overall distribution of regional ecological environment quality was quite different, with the ecological environment quality level showing a decreasing trend from low to high altitude; $\mathrm{RSEI}_{0}$ spatial heterogeneity at the optimal scale of $2 \mathrm{~km}$ was the largest, and the nugget effect was $88 \%$ which indicated a high degree of spatial variability, mainly affected by structural factors; (3) Slope, relief amplitude, elevation, the proportion of high-vegetation area, proportion of construction land area, and average population density significantly impact the spatial differentiation of $\mathrm{RSEI}_{0}$. The explanatory powers of slope and relief amplitude were $56.1 \%$ and $65.3 \%$, respectively, which were the main factors affecting the spatial differentiation of the ecological environment quality in high undulation. The results can provide important scientific support for ecological environment construction and ecological restoration in the study area.

Keywords: China's North-South Transitional Zone; eco-environmental quality; remote sensing monitoring; regional policy coordination; climate change

\section{Introduction}

The ecological environment is a complex system formed by the interaction between natural and social factors. The ecological environment is a characteristic of the comprehensive performance of each element and its function, and it is also the resource and environmental basis for human survival and development [1]. No single environmental element can scientifically and objectively reflect the quality of the ecological environment [2,3]. Eco-environmental quality is one of the important types of ecosystem service functions, and maintaining the stability of its functions is crucial to ecological environmental protection and the integration of natural resources. In particular, the mountains, which characterize a unique geographical unit of the earth's land surface, have a fragile ecological environment 
and are more sensitive to global changes. They are the "amplifiers" of global change signals. Changes in the quality of the mountain ecological environment have an important impact on the surrounding areas [4]. The potential factors affecting the ecological environment of mountainous areas are currently dominated by climate and topography. Their changes have varying degrees of impact on the quality of the ecological environment [5]. In addition, the mountain ecological environment is affected more by environmental problems such as soil erosion, forest degradation, and land desertification than other areas; the heterogeneity of the mountain itself and the negative interference by human beings have exacerbated the vulnerability of the ecological environment [6-8]. Therefore, studying the impact mechanism of mountain ecological and environment assessment is of great significance in constructing an ecological civilization and estimating the value of ecosystem services.

Satellite remote sensing technology has been widely used in ecological environment monitoring and environmental assessment in recent years, based on the high speed of remote sensing satellites and the macroscopic nature of real-time monitoring of the ground truth, and many scholars have used remote sensing indexes to assess the urban ecological environment [9-11], ecological demonstration area [12], aquatic environment [13], and terrestrial surface vegetation [14-16], and have obtained important theoretical results. However, the index selection is relatively single, mainly because the natural environment is a more complex ecological environment. The indicators selected for fragile areas lack scientific knowledge, and it is impossible to grasp the overall habitat quality from a macro perspective. Subsequently, the ecological environment evaluation index (EI) issued by the Ministry of Environmental Protection in 2006 has been widely used in China. Still, the determination of the weight value of the method and the setting and acquisition of the index is very simple [17], making it impossible to visualize the quality of the regional ecological environment. It cannot monitor the spatial change characteristics of the ecological environment any better [18]. Second, many studies are based on multi-angle evaluation methods, using comprehensive evaluation methods such as the fuzzy evaluation method and the analytic hierarchy process (AHP) to analyze the ecological environment and its quality standards; however, human subjectivity is strong, and it is widely used in research and cannot be sufficiently compared with regional differences. When studying the differences between regions, it is difficult to comprehensively evaluate the ecological environment quality using multiple composite factors $[19,20]$. Xu proposed a remote sensing technology-based regional, remote sensing ecological index (RSEI) in 2013 [11,21]. The calculation of this index is relatively convenient, and multiple environmental index factors are considered comprehensively, which can compensate for the suitability of the subjective analysis method for areas with more complex geographical environments. In recent years, it has been widely used by many scholars in the detection and evaluation of temporal and spatial changes in ecological environment quality [20,22-25]. However, systematic analysis of regional ecology research on the impact of environmental quality change and its driving factors is relatively scarce. The spatial differentiation characteristics of mountain ecological and environmental quality have rarely been studied. Therefore, the use of RSEI has important scientific and practical significance for research on the spatial difference of the mountain ecological environment quality at a mesoscale, which is conducive to an accurate understanding of the ecological environment problems in mountainous areas and for the better development of research.

The Qinling-Daba Mountains are the main components of China's North-South Transitional Zone. The mountains are undulating and the vegetation coverage is relatively high. Abundant vegetation and water resources and diversified wild animal resources have created a complex ecological and geographical environment. As a natural barrier for ecological security in central China, an important ecological function area, its natural ecosystem is typicality and representativeness [26]. The quality of the ecological environment is critical. Current research is mostly based on areas such as southern Shaanxi [27], Taibai Mountain [28], and single administrative units [9], discussing the human factors of ecological environment degradation and the scientific nature of the regional ecological envi- 
ronment quality index system, based on the research of land use ecological risk assessment. There is no specific discussion on the quality of the ecological environment based on the Qinling-Daba Mountains as a whole, which leads to relatively imprecise research on the ecological environment of the area. Therefore, it is impossible to look at the trend as a whole. In addition, the study found that the analysis of different scale features and the selection of indicators are very important [29], considering that the Qinling-Daba Mountains are mesoscale regional mountainous landforms, the vegetation coverage is moderate, and the distribution of water and heat is different according to the terrain gradients. For this reason, the normalized vegetation index, the tasseled cap transformation humidity index, the bare soil index, the man-made building index, and the surface temperature were selected as the main factors to explore the spatial distribution of ecological quality based on remote sensing data and its impact mechanism. Finally, whether Structural factors or random factors affect the quality of the ecological environment, and how the local characteristics of the region lead to this process. Whether the research in this area can supplement the shortcomings and deficiencies of other scholars, and how it is different from other studies, are worthy of exploration. Therefore, this study uses the Qinling-Daba Mountains as the research area, based on the 2017 Landsat 8 OLI/TIRS remote sensing images, and uses the special principal component analysis method to construct the regional RSEI to comprehensively evaluate the ecological environment quality of the Qinling-Daba Mountains, analyze the spatial pattern and differentiation characteristics of the ecological environment quality, and systematically explore the potential factors affecting ecological and environmental quality. This study can explore a set of comprehensive remote sensing monitoring methods to monitor ecological environment changes in the areas. It aims to provide theoretical guidance and decision support for managers regarding soil erosion control, disaster prevention, and ecological environment restoration in the area and promote the sustainable development of the regional ecological environment.

\section{Materials and Methods}

\subsection{Study Area}

The study areas range from $30^{\circ}-36^{\circ} \mathrm{N}$ and $101^{\circ}-114^{\circ} \mathrm{E}$ to the east of the Qinghai-Tibet Plateau in the west, the eastern plain in the east, the southern edge of the Loess Plateau, and the northern Sichuan Basin, with the Qinling and Daba Mountains as the main body. It is approximately $300 \mathrm{~km}$ from north to south, with a span of nearly $1000 \mathrm{~km}$ from east to west, a total area of approximately $300,000 \mathrm{~km}^{2}$, covering the six provinces of Sichuan, Henan, Gansu, Shaanxi, Chongqing, and Hubei. The terrain slopes from west to east (Figure 1). The climate is dominated by the subtropical monsoon climate, high vegetation coverage, and rich biodiversity. It is in the transition zone between subtropical and warm temperate zones [30]. Affected by geographical location and mountain topography, the special area has a unique ecological and geographic environment, and has become an important ecological function area in the country. The average net primary productivity (NPP) of vegetation refers to the remainder after deducting autotrophic respiration from the total amount of organic dry matter produced by photosynthesis in a unit of time and area. It represents the vegetation growth status. The average net primary productivity of the areas has increased annually, forming an ecological environment pattern made of a multi-dimensional zonal landscape [31].

\subsection{Data Source and Processing}

The remote sensing data in this study area were obtained from the OLI image of the geospatial data cloud Landsat 8, with a spatial resolution of $30 \mathrm{~m}$, involving 26 images of the study area from March to August 2017. The cloud cover of the images was less than 5\%, and they were concentrated in the spring and summer, without falling leaves. The seasons are similar to each other, which can avoid the influence of seasonal differences. The overall workflow is shown in Figure 2. 


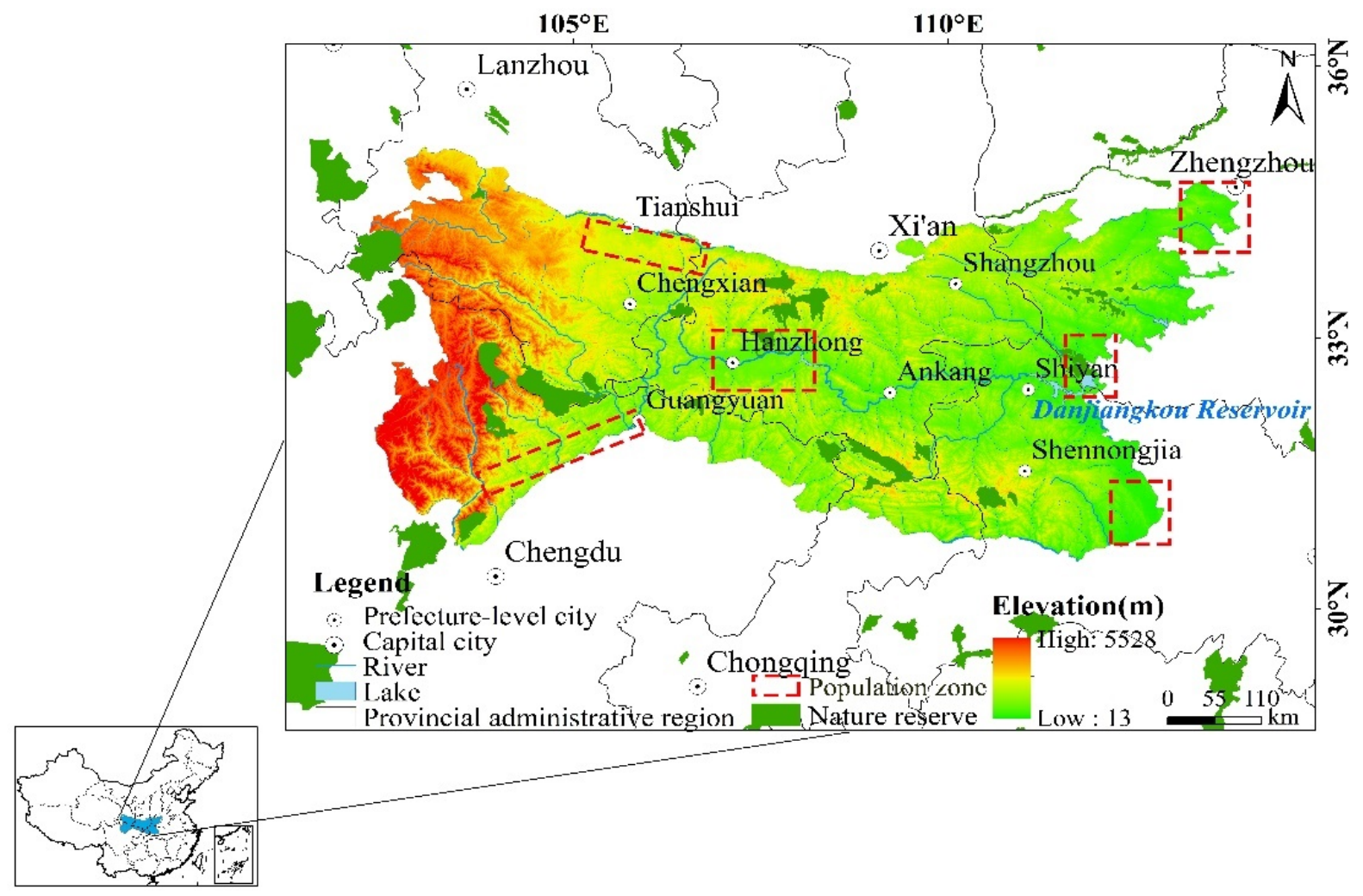

Figure 1. Geographical location of study area.

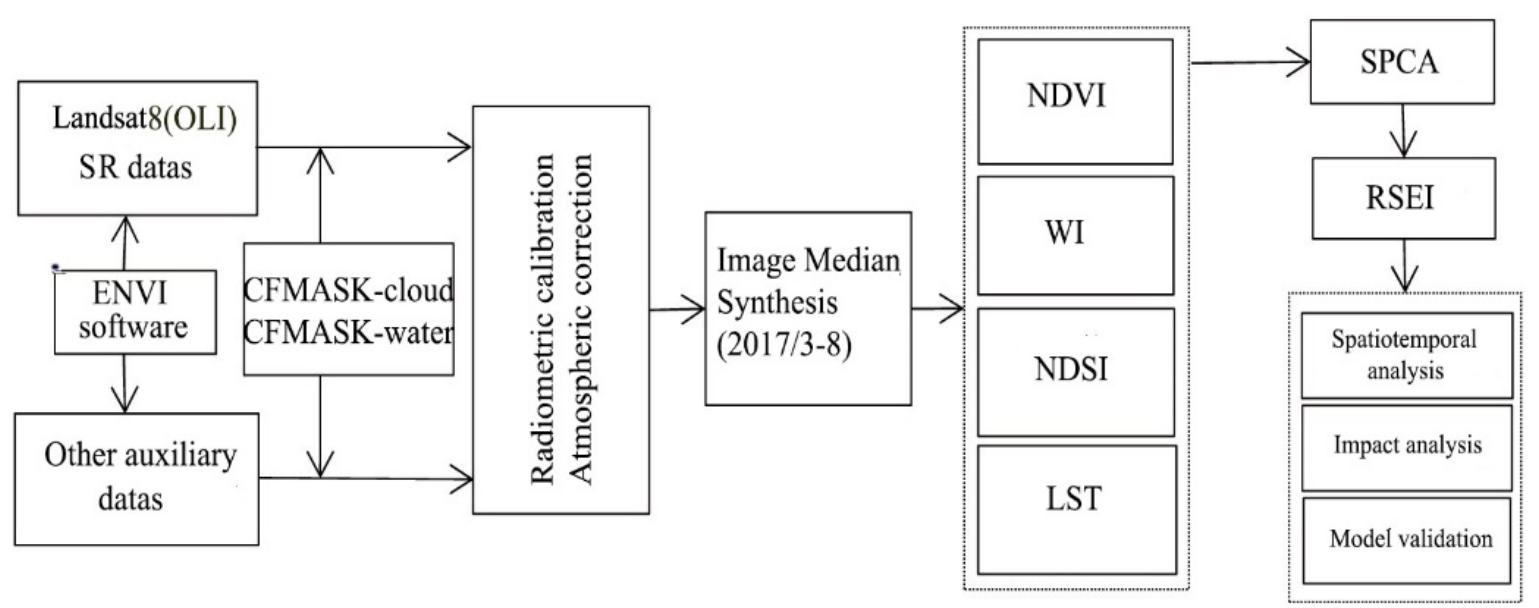

Figure 2. Technical roadmap. NDVI: normalized vegetation; WI: tasseled cap transformation humidity; NDSI: construction index; LST: land surface temperature; SPCA: spatial principal component analysis; RSEI: remote sensing ecological index.

The land cover data of the study area in 2017 comes from the FROM-GLC10 dataset developed by the Department of Earth System Science of Tsinghua University (http:/ / data. ess.tsinghua.edu.cn) (accessed on 11 October 2020), with a spatial resolution of $10 \mathrm{~m}$; the meteorological data is from China Meteorology. The daily value data of the Science Data Center (http: / / data.cma.cn) (accessed on 15 October 2020) are interpolated to obtain a raster dataset; the soil organic carbon data is in the Harmonized World Soil Database (HWSD) (http: / / www.fao.org/land-water/en) (accessed on 23 October 2020), the spatial resolution is 30 arc seconds, and the data of the entire study area is obtained by stitching and cutting; the soil erosion data of the study area are obtained according to previous studies [32]. The socio-economic data for 2017 is based on the 2015 annual average population and GDP, 
and is replaced by raster data, both from the Resource and Environment Data Center of the Chinese Academy of Sciences (http:/ / www.resdc.cn) (accessed on 25 May 2020), with a resolution of $1 \mathrm{~km}$; the DEM data comes from NASA_SRTM with a spatial resolution of $90 \mathrm{~m}$. In the data set, the elevation, slope, and curvature-related data information are extracted. Combined with the actual situation of the study area, the average change-point method is used to extract the relief amplitude data of the areas. The input variables of the Geodetector are categorical, and the terrain relief amplitude is divided into six levels [33]: flat $(<30 \mathrm{~m})$, mesa $(30-70 \mathrm{~m})$, hills $(70-200 \mathrm{~m})$, small undulating mountains $(200-500 \mathrm{~m})$, medium undulating mountains (500-1000 m), and large undulating mountains (>1000 m). Other influencing variables are divided into six categories by the ArcGIS natural breakpoint method so that the results of the impact factors at all levels are comparable in the case of stratification. The results for each Geodetector category component are shown in Figure 3.

a
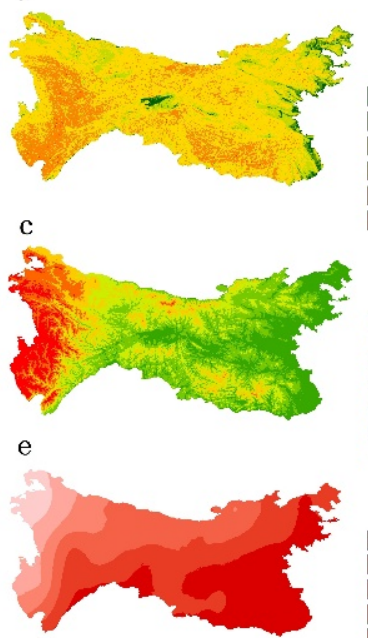

$\mathrm{g}$
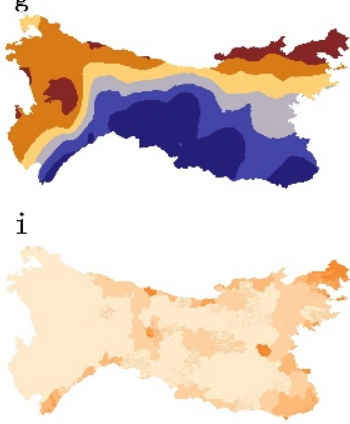
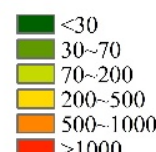

$>1000$

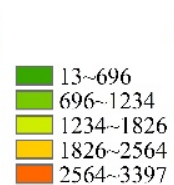

$3397 \sim 5528$
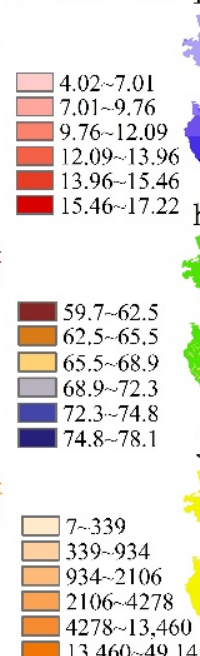
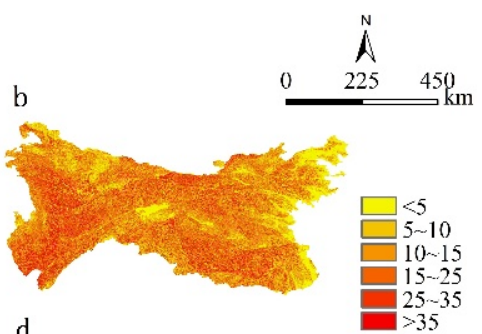

d

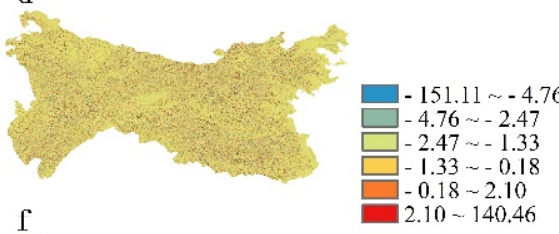

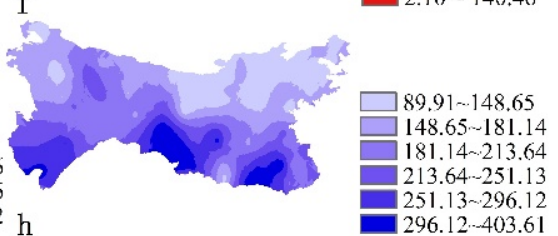
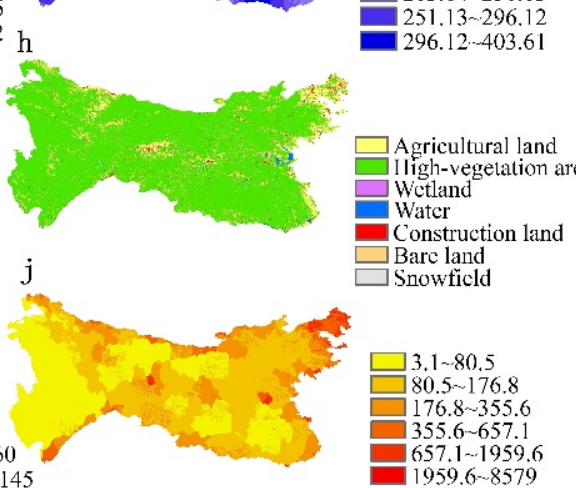

Figure 3. Distribution of each factor class of the Geodetector in Qinling-Daba Mountains. (a) Relief $(\mathrm{m}) ;(\mathbf{b})$ slope $\left({ }^{\circ}\right) ;(\mathbf{c})$ elevation $(\mathrm{m}) ;(\mathbf{d})$ curvature; $(\mathbf{e})$ mean annual temperature $\left({ }^{\circ} \mathrm{C}\right) ;(\mathbf{f})$ mean annual precipitation (mm); (g) mean annual relative humidity (\%); (h) land use types; (i) mean annual GDP (yuan $\mathrm{km}^{-2}$ ); (j) Mean annual population density (person $\mathrm{km}^{-2}$ ).

\subsection{Methodology}

\subsubsection{Selection of Various Index Factors of RSEI}

This study selected the normalized vegetation index, changing the constitution of the tasseled cap, Bare soil index, Construction Index, and Surface Temperature from the perspectives of vegetation, soil, human activities, and climate [13,21]. Combining the spatial principal component analysis (SPCA) to construct the RSEI of the study area, the spatial differentiation of the ecological environment quality of the Qinling-Daba Mountains was assessed (Table 1) [34]. 
Table 1. RSEI evaluation index and its calculation formula.

\begin{tabular}{cc}
\hline Index & Calculation Formula \\
\hline Greenness & $\mathrm{NDVI}=(\mathrm{NR}-\mathrm{NIR}) /(\mathrm{NR}+\mathrm{NIR})$ \\
Humidity & $\mathrm{WI}=0.1511 \mathrm{~B}+0.1973 \mathrm{G}+0.3283 \mathrm{NR}+0.3407 \mathrm{NIR}-0.7117 \mathrm{M}_{1}-0.4559 \mathrm{M}_{2}$ \\
& $\mathrm{NDSI}=(\mathrm{SI}+\mathrm{NDIBI}) / 2$ \\
& $\mathrm{SI}=\left[\left(\mathrm{M}_{1}+\mathrm{NR}\right)-(\mathrm{NIR}+\mathrm{B})\right] /\left[\left(\mathrm{M}_{2}+\mathrm{NR}\right)+(\mathrm{NIR}+\mathrm{B})\right]$ \\
Bare soil and construction & $\mathrm{NDIBI}=\left\{2 \mathrm{M}_{1} /\left(\mathrm{M}_{1}+\mathrm{NIR}\right)\left[\mathrm{NIR} /(\mathrm{NIR}+\mathrm{NR})+\mathrm{G} /\left(\mathrm{G}+\mathrm{M}_{1}\right)\right]\right\} /\left\{2 \mathrm{M}_{2} /\left(\mathrm{M}_{2}+\mathrm{NIR}\right)+\right.$ \\
& $\left.\left[\mathrm{NIR} /(\mathrm{NIR}+\mathrm{NR})+\mathrm{G} /\left(\mathrm{G}+\mathrm{M}_{2}\right)\right]\right\}$ \\
$\mathrm{LST}=\mathrm{T} /[1+(\lambda \mathrm{T} / \rho) \ln \varepsilon-273$ \\
$\mathrm{T}=\mathrm{B}_{2} / \ln \left(\mathrm{B}_{1} / \mathrm{H}_{\mathrm{t}}+1\right)$ \\
Land surface temperature & $\mathrm{H}_{\mathrm{t}}=\left(\mathrm{L}_{\mathrm{t}}-\uparrow \mathrm{U}-\mathrm{V}(1-\varepsilon) \downarrow \mathrm{D}\right) / \mathrm{V}_{\varepsilon}$ \\
&
\end{tabular}

Note: $B, G, N R, N I R, M_{1}, M_{2}, T, K, \rho, \lambda, \varepsilon, H_{t}, B_{1}, B_{2}, L_{t}, \uparrow U, \downarrow D, V$ represent the reflectance of the Landsat 8 remote sensing image in bands $2,3,4,5,6$, and 7 , the surface brightness temperature $\left(\mathrm{K}=1.38 \times 10-23 \mathrm{~J} \cdot \mathrm{K}^{-1}\right)$ $\rho=1.438 \times 10-2 \mathrm{M} \cdot \mathrm{K}$ ( $\mathrm{M}$ is the default constant parameter set by the platform),the center wavelength of the OLI thermal infrared band $(\lambda=11.45 \mu \mathrm{m})$, the surface emissivity image $(\varepsilon)$, the radiation value of the pixel in thermal infrared 10 band at the sensor, the calibration parameters $\left(B_{1}, B_{2}\right)$, the thermal infrared band radiance image $\left(\mathrm{L}_{\mathrm{t}}\right)$, upward radiance value and downward radiance value $\left(\uparrow \mathrm{U}=1.64 \mathrm{~W} /\left(\mathrm{m}^{2} \cdot \mathrm{sr} \cdot \mu \mathrm{m}\right), \downarrow \mathrm{D}=2.75 \mathrm{~W} /\left(\mathrm{m}^{2} \cdot \mathrm{sr} \cdot \mu \mathrm{m}\right)\right)$, atmospheric profile thermal infrared transmittance $(\mathrm{V}=0.78)$.

In this study, the NDVI, closely related to the leaf area index, surface vegetation, and biomass, is widely used to study vegetation and environmental changes as the greenness index [35].

Second, based on OLI land imager data, this study uses the tasseled cap change correlation coefficient method [36], combined with Gram-Schmidt and Prueck correlation algorithms, to obtain the study area atmospheric reflectivity remote sensing data. Regarding the OLI coefficient of variation method, the calculation results show that the accuracy is relatively high, and it has good sorting properties for ground objects [37]. It reflects the abundance of moisture in the soil, water bodies, and vegetation in the study area.

Third, to better characterize the degree of "Dryness" of natural and anthropogenic land in the study area, this study uses the bare soil index [38] and the building index [39] to indicate the dryness components. It takes the average value of the indexes for the quantitative calculation, which represents the natural area of the region and the ecological degradation caused by human activities.

Finally, the temperature component in this study is derived from the ground radiation ratio and the ground surface temperature corrected by the black body image grayscale, which can better quantify the energy exchange parameters between the surface image and the atmosphere and more accurately reflect the surface temperature. Therefore, using the atmospheric correction method to retrieve land surface temperature [40]. $\varepsilon$ is estimated based on the NDVI and vegetation coverage image according to the Landsat model [41]. T was calculated using the Landsat model manual and the latest revised calibration parameter method $[42,43]$. It should be noted that, before calculating the blackbody radiance value, it is necessary to perform radiometric calibration and surface emissivity correction and select the Landsat 8 calculation formula to invert the ground temperature. We referred to the previous improved single-channel algorithm (SC algorithm) to verify and check the ground surface temperature [44]. The last three parameters mentioned above can be queried through the NASA website (http:/ / atmcorr.gsfc.nasa.gov) (accessed on 3 October 2020) to obtain atmospheric profile parameter information.

\subsubsection{Construction of Comprehensive Index of Ecological Environment Quality Evaluation}

In this study, the SPCA was used to couple the above four indicators to eliminate the high correlation between variables to reduce the inaccuracy of information caused by anthropogenic factors; the indicators were normalized through a unified dimension, and the initial study area was obtained. The initial $\mathrm{RSEI}_{0}$ was normalized again to obtain the final comprehensive index RSEI. 
Positive normalization processing formula:

$$
\mathrm{N}_{\mathrm{i}}=\frac{\mathrm{M}_{\mathrm{i}}-\mathrm{I}_{\min }}{\mathrm{I}_{\max }-\mathrm{I}_{\min }}
$$

Reverse normalization processing formula:

$$
\mathrm{N}_{\mathrm{i}}=\frac{\mathrm{I}_{\max }-\mathrm{M}_{\mathrm{i}}}{\mathrm{I}_{\max }-\mathrm{I}_{\min }}
$$

The initial $\mathrm{RSEI}_{0}$ is obtained by principal component analysis:

$$
\mathrm{RSEI}_{0}=\mathrm{PC}_{1}[\mathrm{f}(\mathrm{NDVI}, \mathrm{WI}, \mathrm{NDSI}, \mathrm{LST})]
$$

Then normalize $\mathrm{RSEI}_{0}$ :

$$
\mathrm{RSEI}=\frac{\mathrm{RSEI}_{0}-\mathrm{RSEI}_{0 \text { min }}}{\mathrm{RSEI}_{0 \max }-\mathrm{RSEI}_{0 \text { min }}}
$$

where $M_{i}$ and $N_{i}$ represent the pixel values of $R_{S E I}$ before and after normalization, respectively; $I_{\max }$ and $I_{\min }$ represent the maximum and minimum values of the image, respectively, and $\mathrm{PC}_{1}$ represents the first principal component of the four indicators.

\subsubsection{Spatial Heterogeneity Analysis Method of Ecological Environment Quality}

Because natural and human factors have different degrees of impact on the environmental quality of mountainous areas, to distinguish the impact of structural factors and random factors on the ecological and environmental benefits of the areas and their structural degrees, this study uses a semi-variance function to analyze the degree of spatial differentiation and structural characteristics quantitatively. The image was gridded and sampled based on the optimal research scale of $2 \mathrm{~km}$, and a $2 \mathrm{~km}$ scale spatial structure model was constructed. Based on whether the GS+9.0 conforms to the normal distribution and following the removal of a few sample points that do not meet the normal distribution, the square root conversion conforms to the normal distribution and meets the requirements of semi-variance function analysis. The semi-variance function formula is as follows:

$$
\mathrm{F}(\mathrm{h})=\frac{1}{2 \mathrm{I}(\mathrm{h})} \sum_{\mathrm{i}=1}^{\mathrm{I}(\mathrm{h})}\left[\left(\mathrm{W}\left(\mathrm{C}_{\mathrm{i}}\right)-\mathrm{W}\left(\mathrm{C}_{\mathrm{i}}+\mathrm{h}\right)\right)\right]^{2}
$$

where $F(h)$ is the value of the semi-variance function with $h$ as the distance, $h$ is the sample point spacing, $\mathrm{I}(\mathrm{h})$ is the number of sample pairs divided by the distance point, and $\mathrm{W}\left(\mathrm{C}_{\mathrm{i}}\right)$ and $W\left(C_{i}+h\right)$ are located in the range of $C_{i}$ and $C_{i}+h$ interval variables. The "Nugget effect" refers to the proportion of spatial autocorrelation heterogeneity at a scale. When $\mathrm{C} / \mathrm{C}_{0}+\mathrm{C}<0.25$, the spatial correlation is weak, indicating that the spatial variation caused by the random part plays a major role, and the spatial heterogeneity is weak. When $\mathrm{C} / \mathrm{C}_{0}+\mathrm{C}$ is between 0.25 and 0.75 , the degree of correlation is moderate, and its spatial variability is determined by both random and structural factors. When $C / C_{0}+C>0.75$, the spatial correlation is very strong, and its spatial variability is mainly caused by structural factors, and the degree of spatial heterogeneity is relatively large [45-47].

By combining the above sorting results, this study uses the factor detection of Geodetector to analyze the influence of each geographical element on the ecological environment of the Qinling-Daba Mountains to further study the independent interpretation of the influencing factors of the ecological environment quality to obtain the main factors affecting the differentiation of the mountain ecological environment quality. The formula for the influence degree of mass spatial heterogeneity is as follows:

$$
\mathrm{q}=1-\frac{1}{\mathrm{D} \alpha_{\mathrm{i}}^{2}} \sum_{\mathrm{i}=1}^{\mathrm{n}} \mathrm{Di} \alpha_{\mathrm{i}}^{2}
$$


where $\mathrm{q}$ is the degree of influence of each influencing factor on the spatial distribution of the area's ecological quality, $q \in[0,1], \mathrm{D}$ is the total number of samples in the study area, $\alpha_{\mathrm{i}}{ }^{2}$ is the variance of the sub-regional ecological, environmental quality indicators, $i=1,2 \ldots n, i$ represents each secondary partition, and $n$ represents the number of all partitions. The size of $q$ reflects the degree of spatial heterogeneity of the ecological environment quality in the area. The larger the value of $q$, the stronger the heterogeneity within the spatial partition. The various factors of the partition have a greater impact on the spatial distribution of the ecological environment quality and vice versa. In particular, when $q=0$, it indicates no spatial heterogeneity in the ecological environment quality of the study area; when $q=1$, it indicates perfect spatial heterogeneity. Geodetectors can perform a significant test for the $\mathrm{q}$ value [48].

\subsubsection{Eco-Environmental Quality Index (EQI) Verification}

To verify how scientific and accurate the value of RSEI is in this study, EQI is combined with possible influencing factors, and principal component analysis is used to couple and analyze multiple environmental indicators [49], as follows:

$$
\mathrm{EQI}=\mathrm{SPCA}\{\mathrm{f}(\mathrm{TEM}, \mathrm{PRE}, \mathrm{TI}, \mathrm{LAND}, \mathrm{SL}, \mathrm{SOM}, \mathrm{POP}, \mathrm{GDP})\}
$$

where TEM and PRE are the average annual temperature and annual precipitation in the study area, respectively, TI is the topographic index based on slope and altitude, LAND is the land use degree, SL is the soil erosion intensity, SOM is the soil organic matter content, and POP and GDP are the population density and total GDP, respectively.

\section{Results}

\subsection{Principal Component Analysis Results of RSEI Index in Qinling-Daba Mountains}

To comprehensively study the quality of the ecological environment of the QinlingDaba Mountains in 2017, according to the research classification standard of Xu Hanqiu [21], the RSEI is divided into excellent (0.8-1.0), good (0.6-0.8), middle (0.4-0.6), poor (0.2-0.4), and very poor $(0-0.2)$.

Principal component analysis was performed using the ENVI software to obtain the covariance matrix and correlation coefficient matrix of each component. The eigenvalues and contribution rates are presented in Table 2 . It shows that the cumulative contribution rate of $\mathrm{PC}_{1}$ has reached more than $85 \%$, indicating that it has concentrated on the main characteristics of the four indicators, and the first principal component can be used to replace the four indicators. The overall RSEI average of the Qinling-Daba Mountains reached 0.61, and the overall ecological environment quality was at a "good" level. It can be seen from the $\mathrm{PC}_{1}$ load values of the four component indicators that the greenness NDVI and humidity WI are positive in the overall load, and the dryness NDSI and heat LST are negative. Consistent with the fact that greenness and humidity positively affect the quality of the ecological environment, dryness and heat negatively affect the environmental quality [24,50-52]; the load value of $\mathrm{PC}_{2}-\mathrm{PC}_{4}$ can be of different sizes and cannot represent the overall component well. Among the positive indicators, the average value of NDVI was 0.63 , and its contribution to the indicator was 0.614 . It has the largest contribution of all indicators, suggesting that vegetation plays a vital role in the quality and maintenance of the ecological environment of the area. Humidity is second only to greenness in the ecological environment of the Qinling-Daba Mountains. The load value of $\mathrm{PC}_{1}$ was relatively low, whereas $\mathrm{PC}_{2}$ was relatively large and negative. Such findings contrast the large wetland in the area located in the urban concentration area with the low humidity in the high-altitude zone; humidity is affected by terrain and is man-made. Among the negative indicators, heat has a large negative impact on the ecological environment quality of the overall study area, and loads of $\mathrm{PC}_{1}$ and $\mathrm{PC}_{2}$ are opposite, indicating that appropriate temperature and light have a positive effect on vegetation and biological growth. However, affected by geomorphic features and aspects, vegetation and soil moisture will evaporate faster, and the habitat benefit will gradually decline. 
Table 2. Results of RSEI and its indicators.

\begin{tabular}{|c|c|c|c|c|c|c|c|}
\hline Index & Mean & $\begin{array}{l}\text { Standard } \\
\text { Deviation }\end{array}$ & $\mathrm{PC}_{1}$ & $\mathrm{PC}_{2}$ & $\mathrm{PC}_{3}$ & $\mathrm{PC}_{4}$ & $\begin{array}{c}\mathrm{PC}_{1} \text { Load } \\
\text { Value }\end{array}$ \\
\hline NDVI & 0.63 & 0.27 & 0.614 & 0.133 & 0.427 & 0.654 & 0.614 \\
\hline WI & 0.54 & 0.16 & 0.232 & -0.971 & 0.233 & 0.048 & 0.232 \\
\hline NDSI & 0.40 & 0.20 & -0.521 & -0.194 & -0.826 & 0.094 & -0.521 \\
\hline LST & 0.58 & 0.29 & -0.597 & 0.030 & 0.285 & -0.749 & -0.597 \\
\hline Eigenvalues & - & - & 0.193 & 0.023 & 0.005 & 0.004 & - \\
\hline $\begin{array}{c}\text { Eigenvalue } \\
\text { Contribution rate (\%) }\end{array}$ & - & - & 85.41 & 10.29 & 2.31 & 1.99 & - \\
\hline RSEI & 0.61 & 0.10 & - & - & - & - & - \\
\hline
\end{tabular}

\subsection{The Spatial Distribution Characteristics of RSEI in Qinling-Daba Mountain Area}

It can be seen from Figure 4 that the ecological environment quality of the Qinling-Daba Mountains in 2017 is significantly different: excellent areas are scattered in the Shennongjia forest area, western Henan Mountains, Taibai Mountain, and western high-altitude areas, covering Shennongjia, Taibai Mountain, Baotianman, Funiu Mountain nature reserves, and Lianhuashan in Gansu. They have good natural vegetation growth and high ecological environment quality. The poor areas are mainly distributed in the middle and low altitude areas in the northwestern part of the west. The central Hanzhong area, and the areas along the eastern line, with relatively concentrated areas, are generally located in the fringe areas of cities, such as Hanzhong City, Danjiangkou City, Shiyan City, Nanyang City, and other important urban areas.

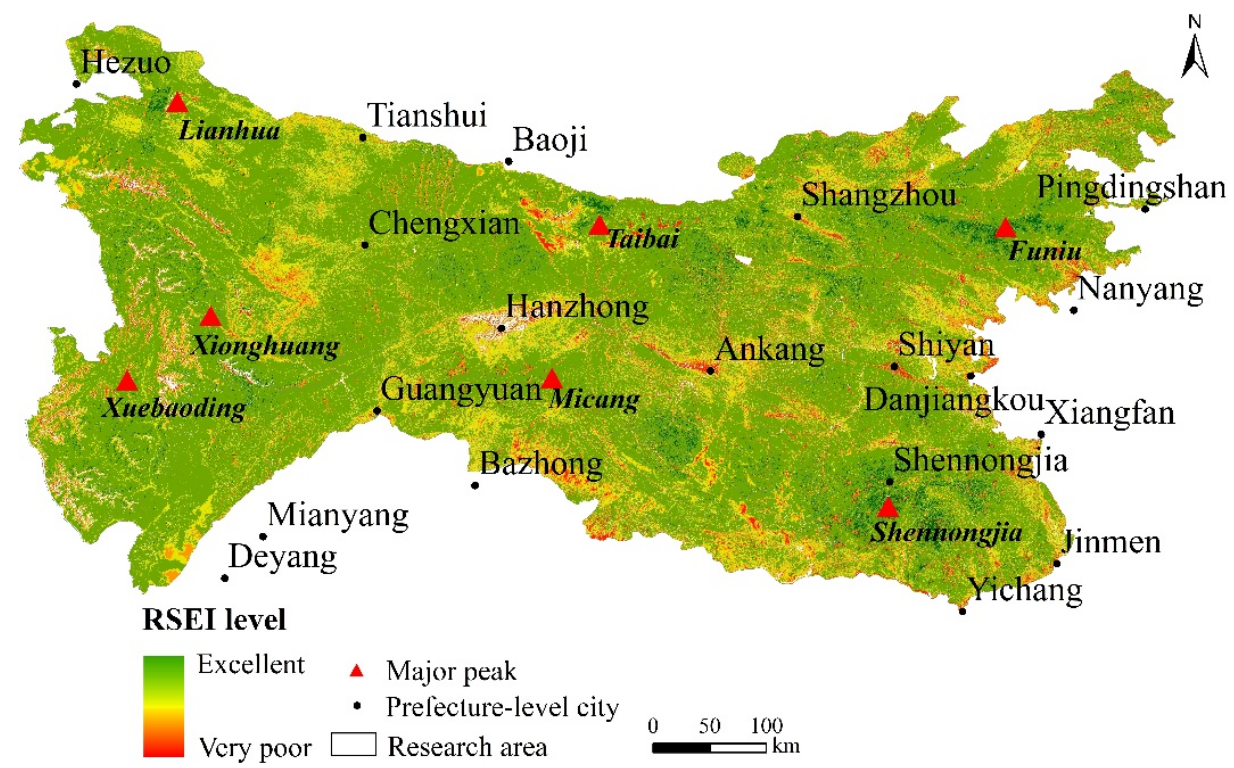

Figure 4. Spatial distribution of eco-environmental quality in Qinling-Daba Mountains by remote sensing.

Table 3 shows the area and proportion of each quality grade of the ecological environment in the study area (water area was not included). Among the various grades of the area ecological environment quality, good (0.6-0.8) and medium (0.4-0.6) are $17.9 \times 10^{4} \mathrm{~km}^{2}$ $(63.14 \%)$ and $8.2 \times 10^{4} \mathrm{~km}^{2}(29.15 \%)$, respectively, occupying a large proportion. Poor $(0.0-0.2)$, very poor $(0.2-0.4)$, and excellent (0.8-1.0) are $0.3 \times 10^{4} \mathrm{~km}^{2}(1.11 \%), 1.3 \times 10^{4} \mathrm{~km}^{2}$ $(4.54 \%)$, and $0.58 \times 10^{4} \mathrm{~km}^{2}(2.06 \%)$, respectively, accounting for relatively less. The overall distribution characteristics are "small at both ends and big in the middle," and the proportion of excellent-grade and poor-grade areas is relatively small. In contrast, the area of middle-grade areas is larger. According to the characteristics of the terrain, the ecological environment quality of the middle and high altitude $(1000-4500 \mathrm{~m})$ mountainous areas are mainly excellent-grade and middle-grade areas, and the low-altitude $(<1000 \mathrm{~m})$ areas are 
mainly poor or very poor-level areas. The ecological environment quality level shows a decreasing trend from low to high altitude.

Table 3. Area and proportion of remote sensing eco-environmental quality.

\begin{tabular}{ccc}
\hline RSEI Level & Area $\mathbf{( k m}^{\mathbf{2}} \mathbf{)}$ & Proportion $\mathbf{( \% )}$ \\
\hline Very poor $(0 \sim 0.2)$ & 3154.5 & 1.11 \\
Poor $(0.2 \sim 0.4)$ & $12,851.15$ & 4.54 \\
Middle $(0.4 \sim 0.6)$ & $82,487.02$ & 29.15 \\
Good $(0.6 \sim 0.8)$ & $178,672.98$ & 63.14 \\
Excellent $(0.8 \sim 1.0)$ & 5832.89 & 2.06 \\
Total & $282,998.54$ & 100.00 \\
\hline
\end{tabular}

\subsection{The Spatial Differentiation Characteristics of RSEI I under Different Scale Effects}

It can be seen from Figure 5 that the Moran's I shows a single-peak trend, first increasing sharply, before slowly decreasing, with the lowest value being 0.71 ; at the spatial scale of $1 \times 1 \mathrm{~km}, 1.5 \times 1.5 \mathrm{~km}, 2 \times 2 \mathrm{~km}, 2.5 \times 2.5 \mathrm{~km}, 3 \times 3 \mathrm{~km}, 3.5 \times 3.5 \mathrm{~km}$, and $4 \times 4 \mathrm{~km}$, the values are $0.72,0.75,0.78,0.76,0.73,0.72$, and 0.71 , respectively. The Z-score feature trend was similar to Moran's I. All passed the significance test (Z-score $>1.96)$, indicating that $\mathrm{RSEI}_{0}$ has a strong positive spatial correlation at various scales and the spatial heterogeneity is relatively large. Second, the mean and standard deviation of $\mathrm{RSEI}_{0}$ under the seven scales did not change with the scale. The scale had a relatively small impact on the ecological and environmental benefits itself, thus avoiding the inequality of research objects at different spatial scales. The Moran's I reach a maximum at $2 \mathrm{~km}$ of the grid, indicating that $\mathrm{RSEI}_{0}$ has strong spatial aggregation and spatial heterogeneity at this scale. The spatial distribution characteristics of $\mathrm{RSEI}_{0}$ are related to geographical locations so that $\mathrm{RSEI}_{0}$ can study spatial structure characteristics and factor detection.

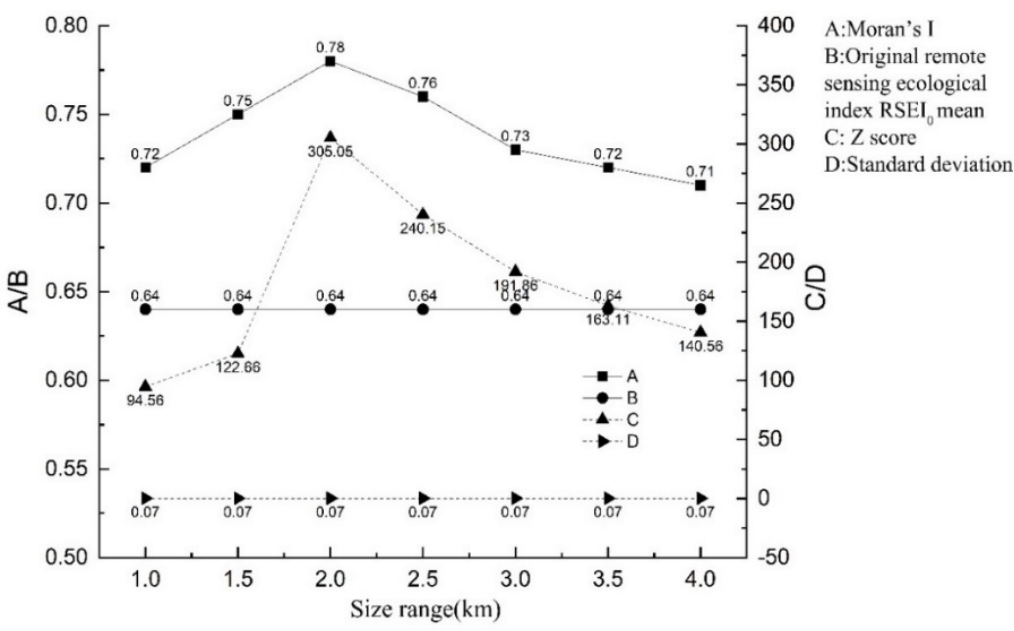

Figure 5. Spatial statistical characteristics of $\mathrm{RSEI}_{0}$ in different scales of Qinling-Daba Mountains.

Table 4 shows that the optimal fitting theoretical model of $\mathrm{RSEI}_{0}$ is the exponential model, the coefficient of determination (R-Square) is 0.80 , the residual error (RSS) is $2.3 \times 10^{-7}$, and its nugget effect is $88 \%$, indicating that a high degree of space heterogeneity is mainly affected by structural factors. Among them, the nugget value $\left(\mathrm{C}_{0}\right)$ of $\mathrm{RSEI}_{0}$ in the study area is relatively small $\left(7.6 \times 10^{-4}\right)$, indicating that factors affect the spatial distribution of ecological environment quality on a small sampling scale. At the same time, the nugget effect $\left(\mathrm{C} / \mathrm{C}_{0}+\mathrm{C}\right)$ exceeded 0.75 , indicating that the spatial heterogeneity dominated by structural factors was relatively large, and the randomness was relatively small. Combined with the Geodetector analysis results, the detection factors of elevation, slope, and relief amplitude were 0.528, 0.561, and 0.653, respectively, all of which passed the two-tailed significance test, which has a greater impact than climate $(0.256,0.312$, and 
0.23) and socio-economic (0.002, 0.174, and 0.214) factors (from Section 3.4). Such findings are due to the vast mountainous area in the study area. Large topographical undulations account for more than $1 / 5$ of the total area, and they are mostly distributed in man-made protected nature reserves and mountain hinterlands. Topographic factors have a significant impact on the quality of the ecological environment. On the best analysis scale, the spatial differentiation of ecological environment quality in different regions is equally large, but it is worth noting that this region is a concentrated area for poverty alleviation under many plains, where urbanization and economic development are relatively slow. Because of the impact of key local engineering constructions such as returning farmland to forests and water and soil conservation in the areas, the ecological environment of the middle and low altitude areas is better than other areas in China, but it is different from other research results such as plateau, arid, and agricultural and pastoral areas [53-56]. Differences and comparisons will be described in the discussion section.

Table 4. $\mathrm{RSEI}_{0}$ Semi-variance function model and its results.

\begin{tabular}{cccccc}
\hline Model & $\mathbf{C}_{\mathbf{0}}$ & $\mathbf{C}_{\mathbf{0}}+\mathbf{C}$ & $\mathbf{C}_{\mathbf{0}}+\mathbf{C}$ & R-Square & RSS \\
\hline Gaussian model & 0.001 & 0.0063 & 83.9 & 0.74 & $2.9 \times 10^{-7}$ \\
Linear model & 0.002 & 0.0071 & 71.0 & 0.34 & $1.7 \times 10^{-7}$ \\
Exponential model & 0.00076 & 0.0064 & 88.0 & 0.80 & $2.3 \times 10^{-7}$ \\
Spherical model & 0.00032 & 0.0060 & 94.9 & 0.74 & $2.9 \times 10^{-7}$
\end{tabular}

\subsection{Factors Influencing Spatial Heterogeneity of RSEI $I_{0}$ in Qinling-Daba Mountains}

In this study, the Pearson correlation analysis method was used to analyze the correlation between each variable. As shown in Table 5 , the $\mathrm{RSEI}_{0}$ in the study area positively correlates with the slope, relief amplitude, elevation, and curvature in the terrain factors, with correlation coefficients of $0.62,0.56,0.52$, and 0.1 , respectively. The slope has the largest contribution rate to the terrain factor, followed by relief amplitude and elevation, indicating that the greater the slope, the higher the elevation, and the greater the relief amplitude, the better the quality of the ecological environment. Conversely, the lower the elevation, the lower the quality of the ecological environment. Among climatic elements, $\mathrm{RSEI}_{0}$ was negatively correlated with annual average temperature and annual precipitation, but positively correlated with relative humidity, consistent with the negative effect of heat on the quality of the ecological environment in the previous article (from Section 3.1). The annual precipitation correlation coefficient was 0.38 , and that of the annual average relative humidity was 0.18 . Although it is consistent with the $\mathrm{PC}_{1}$ load value and the positive correlation with $\mathrm{RSEI}_{0}$, the precipitation and humidity index correlation are different. This difference is because the mask image was extracted from the water area, and the most important wetland areas were removed, so the correlation between humidity and $\mathrm{RSEI}_{0}$ was weakened. Among the land use types, the correlation coefficients of the proportion of high-vegetation area, construction land, and agricultural land were 0.37, 0.33, and 0.09, respectively. Among them, only the proportion of high-vegetation areas had a high positive correlation with $\mathrm{RSEI}_{0}$. The ratio of construction land to agricultural land area is negatively correlated with the quality of the ecological environment, proving that the vegetation areas with higher altitudes mentioned above contribute to the quality of the ecological environment. At the same time, improving the ecological deterioration with high vegetation coverage has a positive effect on the quality of the ecological environment. The expansion of industrial agriculture in low-altitude areas has a restraining effect on the ecological environment of the study area. Among the socio-economic factors, the correlation coefficients between the population density and the average annual GDP are only 0.22 and 0.19, respectively. Both have a negative correlation with $\mathrm{RSEI}_{0}$, indicating that socio-economic development and human activities negatively affect the quality of the regional ecological environment. In summary, slope, elevation, relief amplitude, average annual precipitation, and high-vegetation land use types have a close spatial correlation with $\mathrm{RSEI}_{0}$, which affects the degree of spatial heterogeneity of the ecological environment quality. 
Table 5. $\mathrm{RSEI}_{0}$ and the correlation analysis result of each index factor.

\begin{tabular}{|c|c|c|c|}
\hline Influencing Factor & Analytic Index & Correlation Coefficient & Correlation \\
\hline \multirow{4}{*}{ Terrain factors } & Elevation & 0.52 & + \\
\hline & Slope & 0.62 & + \\
\hline & Curvature & 0.10 & + \\
\hline & Relief amplitude & 0.56 & + \\
\hline \multirow{3}{*}{ Climatic factors } & Average annual temperature & 0.25 & - \\
\hline & Average annual precipitation & 0.38 & - \\
\hline & Annual average relative humidity & 0.18 & + \\
\hline \multirow{3}{*}{ Land use type } & Proportion of high vegetation area & 0.37 & + \\
\hline & Proportion of construction land area & 0.33 & - \\
\hline & Proportion of agricultural land area & 0.09 & - \\
\hline \multirow{2}{*}{ Socio-economic factors } & Annual average GDP & 0.19 & - \\
\hline & Population density & 0.22 & - \\
\hline
\end{tabular}

+: positive; -: negative.

The effect of the influencing factors mentioned above was analyzed by exploring the explanatory power of each influencing factor on the spatial variability of $\mathrm{RSEI}_{0}$ in the Qinling-Daba Mountains based on geographic detectors. As shown in Table 6, slope, elevation, curvature, relief amplitude, annual average temperature, annual average precipitation, annual relative humidity, the proportion of high vegetation area, the proportion of construction land area, and population density affect the ecological environment quality of the study area. The impact of spatial differentiation is more significant, but its explanatory power is different. Among the terrain factors, the interpretation ability of topographic undulation was the highest, reaching $65.3 \%$; the second was elevation and slope, which were $52.8 \%$ and $56.1 \%$, respectively; the weakest interpretation ability was curvature, which was only $2.1 \%$. Among the climatic factors, the interpretation ability of the spatial differentiation of annual average precipitation is higher $(31.2 \%)$; the annual average temperature and relative humidity are second, only $25.6 \%$ and $23 \%$, respectively. Among the land use types, high-vegetation areas accounted for a higher explanation ability $(28.2 \%)$, followed by construction land (13.5\%). Among the socio-economic indicators, the explanatory ability of population density was $21.4 \%$. The spatial heterogeneity of the relief amplitude was relatively high, exceeding $60 \%$. As shown in Figure 6, the average value of $\mathrm{RSEI}_{0}$ in the area increases with the relief amplitude on flat land $(<30 \mathrm{~m})$, mesa $(30-70 \mathrm{~m})$, hills $(70-200 \mathrm{~m})$, and small relief mountains $(200-500 \mathrm{~m})$. However, the sharp increase began slowly after the medium-relief mountain area $(500-1000 \mathrm{~m})$. The change also quickly stabilized, indicating that the overall ecological quality can be quickly improved through adjustment and optimization measures in the medium and small relief mountain areas. The high relief mountain area needs to maintain the current good ecological environment by maintaining the water, soil, and vegetation. In summary, structural factors have a greater impact on the $\mathrm{RSEI}_{0}$ of the Qinling-Daba Mountains. Among them, the spatial differentiation of relief amplitude has the highest interpretation ability. The influence of slope on $\mathrm{RSEI}_{0}$ cannot be underestimated and is consistent with the results of the semi-variance function study. Such results show that the quality of the ecological environment in the study area is restricted by natural factors. The influence of social and economic factors is not enough to offset the changes in the regional mountain ecological environment. The relief amplitude and slope factors can be considered to improve the ecological environment quality of the entire region in the future. 
Table 6. $\mathrm{RSEI}_{0}$ detection results of various influencing factors.

\begin{tabular}{|c|c|c|c|}
\hline Factor Types & Influencing Factor & Detection Index & (q Value) \\
\hline \multirow{7}{*}{ Structural factors } & \multirow{4}{*}{ Terrain factors } & Elevation & $0.528 * *$ \\
\hline & & Slope & $0.561 * *$ \\
\hline & & Curvature & $0.021 * *$ \\
\hline & & Relief amplitude & $0.653 * *$ \\
\hline & \multirow{3}{*}{ Climatic factors } & Annual average temperature & $0.256^{* *}$ \\
\hline & & Annual average precipitation & $0.312 * *$ \\
\hline & & Annual average relative humidity & $0.230 * *$ \\
\hline \multirow{5}{*}{ Randomness factors } & \multirow{3}{*}{ Land use type } & Proportion of high vegetation area & $0.282 * *$ \\
\hline & & Proportion of construction land area & $0.135 * *$ \\
\hline & & Proportion of agricultural land area & 0.002 \\
\hline & \multirow{2}{*}{ Socio-economic factors } & Annual average GDP & 0.174 \\
\hline & & Population density & $0.214^{* *}$ \\
\hline
\end{tabular}

${ }^{* *} p<0.01$.

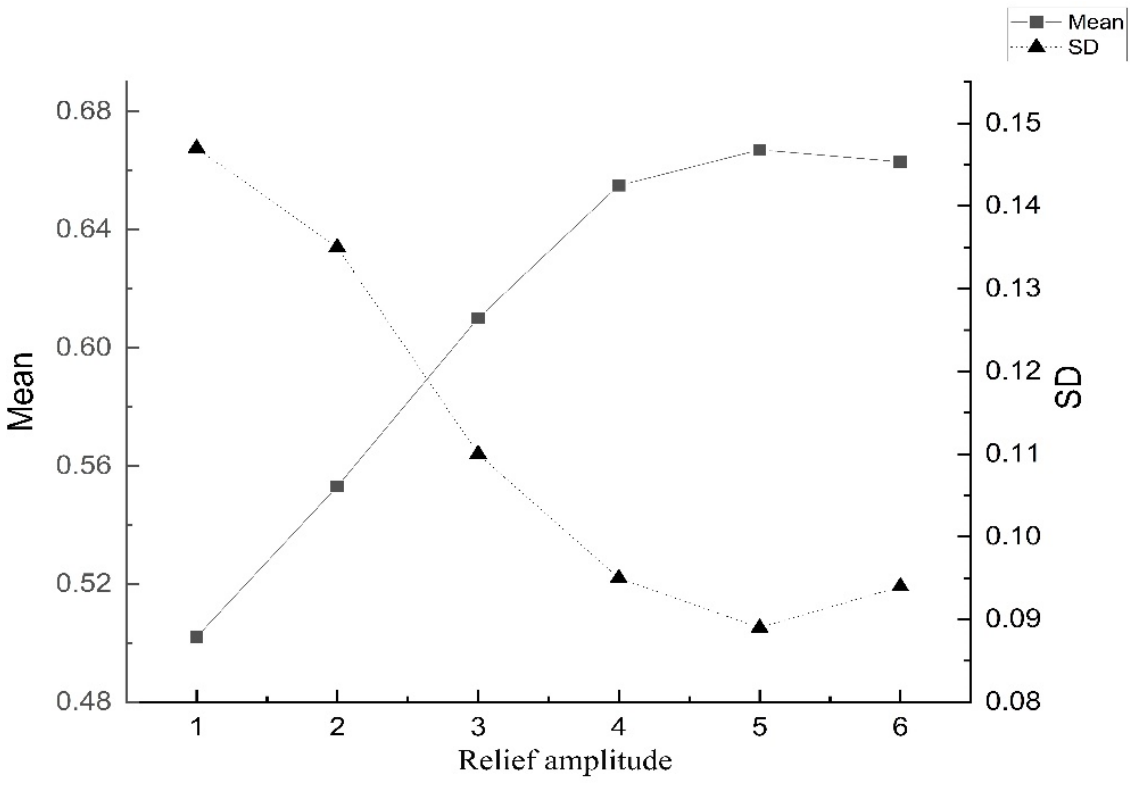

Figure 6. Distribution of mean value of $\mathrm{RSEI}_{0}$ under different relief amplitudes.

\section{Discussion}

\subsection{Verification of the Accuracy of the RSEI Comprehensive Method}

This study use RSEI's comprehensive analysis index to characterize the ecological environment quality of the Qinling-Daba Mountains and analyzes the spatial structure differentiation characteristics and its influencing factors. The advantage of using this method is that a comprehensive index can quantitatively analyze the objects referred to by the index through the linear transformation of the data itself. The transformation algorithm is not obtained by an artificially weighted calculation, which overcomes the subjectivity of artificial evaluation. Second, the whole area has the characteristics of "population gathering" and has different levels of human activities in the complex natural geographical environment [32]. The simple and superimposed ecological environment evaluation method cannot be visualized, and the weight of a single element is relatively large. The method proposed by the present study overcomes this drawback. The analysis results show that the average values of the humidity index, dryness index, and heat index are $0.07,0.21$, and 0.03 , respectively, and are less than the comprehensive index RSEI. The greenness index with the highest contribution is 0.2 , which is higher than that of RSEI. The correlation between the indexes is also very high. These values show that 
this comprehensive index can better integrate the information of each index and is also more representative than any single index, and can adequately reflect the quality of the ecological environment in the area. The EQI also verified the overall spatial distribution trend [49], which is highly fit with RSEI. However, RSEI is better than the verification data in local details, indicating that this comprehensive indicator is suitable for detecting the Qinling-Daba Mountains' ecological environment (Figure 7).

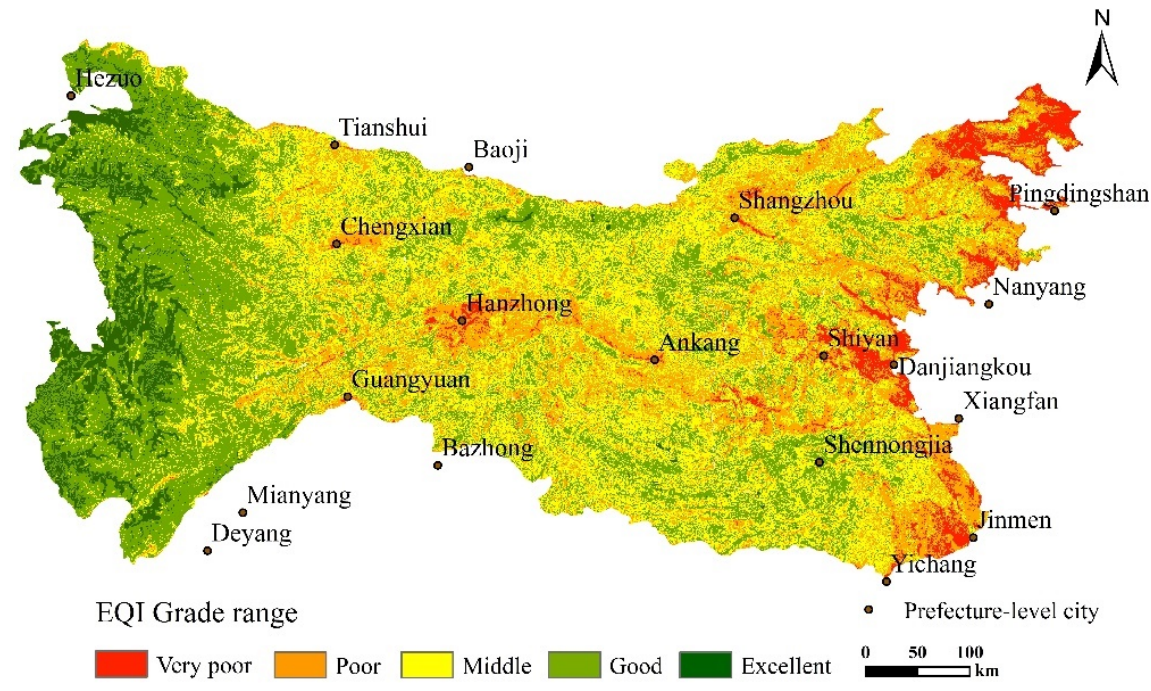

Figure 7. Spatial distribution of ecological environment quality index (EQI).

\subsection{The Rationality of the Selection of Indicators}

In addition, the selection of indicators is scientific and reasonable, affecting the distribution of comprehensive indicators. The NDVI index selected for greenness in this study was due to the large differences in vertical relief in the Qinling-Daba Mountains areas, the longer plant growth seasons under different terrains, and the medium-level vegetation coverage that contributes to the ecological environment; therefore, the use of this index can reduce the detailed problem of special principal component analysis and is suitable for studying the mesoscale area $[29,57]$. The selection of humidity and heat indicators mainly consider the complexity of the areas' climate and the characteristics of the mountain elevation effect mechanism that led to a large difference in heat distribution between the mountain and the plain [58]. This selection is reflected by the differences in the internal and external environments of the mountains, resulting in huge differences in the distribution of humidity and heat, which indirectly affects the quality of the regional ecological environment through biological effects [59]. The selection of dryness includes unused natural wasteland and man-made construction land. Frequent human activities in low-altitude areas in the mountain area and the loss of natural wasteland in high-altitude areas strongly antagonistically affect ecological quality. This indicator takes natural and human factors into account and can be compared with the overall environmental quality, and comprehensively analyzes the spatial differences in ecological, environmental quality.

\subsection{Comparative Analysis and Suggestions on Influencing Factors}

Structural factors have a more important impact on the ecological environment quality of the Qinling-Daba Mountains than random factors, especially the spatial interpretation of relief amplitude and slope, which can reflect the spatial differentiation of RSEI more than other factors. The change characteristics are mainly due to the diverse landform types of the area, and the complex geographic features make the spatial geographic differentiation huge [60]. Vegetation coverage is densely distributed in areas with large relief amplitudes and slopes due to fewer human activities; areas with lower undulations are subject to frequent human disturbances. The ecological environment is restricted by construction and agricultural land. 
At the same time, we found that the explanatory power of the annual average precipitation was $31.2 \%$. In comparison, the explanatory power of the agricultural land area was $0.2 \%$, with a weak negative correlation, which is in accordance with similar studies $[23,55]$. In their results, the ecological environment of agricultural areas was relatively high, and the positive correlation was inconsistent. Such findings are due to intensive and unreasonable farming methods in the lowland plains of the area that hinder the development of the regional ecological environment. We also believe that there are various problems in the regional agricultural ecological environment, including soil pollution caused by chemicals such as pesticides, water pollution caused by breeding and domestic sewage, and backward energy utilization patterns that lead to energy waste and air pollution. In addition, the study time was selected as the spring and summer season, which is the farming season, when the vicinity of the original vegetation environment is affected by farming. These factors led to a weak negative correlation between the quality of the ecological environment and agricultural land.

On the other hand, the explanatory power of annual average temperature, annual average GDP, and population density are $25.6 \%, 17.4 \%$, and $21.4 \%$, respectively, and are negatively correlated with $\mathrm{RSEI}_{0}$, which is more consistent with the results of previous studies [52,61,62]. In view of this result, we all agree that the Qinling-Daba Mountains are one of the most sensitive areas to climate change. The climate varies greatly in some mountainous areas, and the temperature difference is more obvious. Abrupt climate change has a certain impact on the growth of vegetation in the transition zone, especially the increasing trend of extreme and high-temperature weather and the difference in water and heat evaporation caused by slope direction [63], combined with regional warming to reduce the quality of regional habitats to a certain extent. As far as socioeconomic indicators (annual average GDP, population density) are concerned, because the QinlingDaba Mountains area is one area where the poor population is concentrated in China, various social and economic development indicators are relatively weak [64]. The lack of coordination between the natural ecological environment and economic development makes the ecological environment subject to less human disturbance. It maintains a virtuous cycle of the ecosystem in areas with relatively poor economic development [65-68].

At the same time, we also found that the low ecological, environmental quality areas are located near many cities; the expansion of local land scale, infiltration of human activities, unreasonable land planning, the pursuit of the formal economy, and other adverse social reactions have negatively affected the nearby ecological environment. The large areas are located in the transition zone from the northern subtropical to the warm temperate zone [31]. The ecological environment is relatively fragile and sensitive. Although the implementation of many environmental measures has effectively improved the resilience of the mountain ecological environment, the area is suffering in terms of special ecological environment construction. Therefore, we must coordinate the overall situation and pay more attention to the local, regional governance of mountain characteristics, water and soil, and man-made environments.

\subsection{Shortcomings and Prospects}

The disadvantage of this study is that it does not fully explore the deeper index framework of the ecological environment. It only analyzes the quality of the ecological environment on the land surface system without considering the influence of water bodies and human ecological environment index factors. The time phase of remote sensing data does not reach a very high degree of closeness, and there is a certain error in the results of the analysis of RSEI. Moreover, climate change has an important impact on the quality of ecosystems and the ecological environment and should be considered in the future $[69,70]$. Limited by the number of data acquisitions, this study only studies the 2017 Qinling-Daba Mountains' RSEI and its influencing factors and has not carried out multi-dimensional studies on multiple years to reveal its temporal and spatial distribution characteristics. In the future, the quality of the ecological environment in different regions of the Qinling-Daba 
Mountains will be studied on a long-term scale, including research on topography, extreme climate, atmospheric circulation, water body ecological environment, and human effects. The research is mainly based on high-precision spatial resolution remote sensing image data to explore the ecological status of different provinces and urban areas, and to reveal the impact mechanism of atmospheric changes and human activities on the quality of the ecological environment. Future work will continue to advance this research.

\section{Conclusions}

(1) The overall RSEI average value of the Qinling-Daba Mountains reached 0.61, and the ecological environment quality was mostly above the middle level; the greenness contributed the most to the RSEI comprehensive index of the areas, indicating that vegetation coverage plays an important role in the improvement of the ecological environment quality of the areas. Heat has the second-highest contribution to the RSEI index of the area, and it has an inhibitory effect on improving the area's habitat quality.

(2) The overall distribution of ecological environment quality in the study area in 2017 was quite different, with good and bad being distributed alternately from east to west; the ecological environment quality level decreased from low to high altitude. Lowvalue areas accounted for a relatively large area in low-altitude land, and high-value areas accounted for a relatively large area in high-altitude areas.

(3) There are scale changes in the spatial clustering of $\mathrm{RSEI}_{0}$. The degree of spatial heterogeneity is the most obvious at a scale of $2 \mathrm{~km}$. The $\mathrm{RSEI}_{0}$ nugget effect is $88 \%$, which is high spatial heterogeneity, mainly affected by structural factors such as slope, relief amplitude, elevation, curvature, annual average temperature, annual average precipitation, annual average relative humidity, the proportion of high-vegetation areas, proportion of construction land area, and average annual population density which have significant effects on the spatial differentiation of $\mathrm{RSEI}_{0}$. Among them, slope and relief amplitude are the main factors affecting the spatial differentiation of the Qinling-Daba Mountains' ecological environment quality.

Author Contributions: H.Y.: Conceptualization, Writing-original draft. C.C.: Methodology, Writing-review. Q.D.: Data analysis. P.Z. and Q.C.: Software, Visualization. L.Z.: Validation, Supervision, Financial support. All authors have read and agreed to the published version of the manuscript.

Funding: The work presented in this paper was supported by the National Science and Technology Basic Resource Investigation Program of China (Grant No. 2017FY1009002), National Natural Science Foundation of China (Grant No. 41671090).

Institutional Review Board Statement: Not applicable.

Informed Consent Statement: Not applicable.

Acknowledgments: We thank the anonymous reviewers for their constructive comments on the earlier version of the manuscript and the staff of the editorial department for their hard work. We would like to thank our experts for English language editing.

Conflicts of Interest: The authors declare that they have no known competing financial interest or personal relationships that could have appeared to influence the work reported in this paper.

\section{References}

1. Rastorgueff, P.A.; Bellan, S.D.; Bianchi, C.N. An ecosystem-based approach to evaluate the ecological quality of Mediterranean undersea caves. Ecol. Ind. 2015, 54, 137-152. [CrossRef]

2. Imhoff, M.L.; Zhang, P.; Wolfe, R.E.; Bounoua, L. Remote sensing of the urban heat island effect across biomes in the continental USA. Remote Sens. Environ. 2009, 114, 504-513. [CrossRef]

3. Zhao, Q.G.; Huang, G.Q.; Ma, Y.Q. Ecological environment and construction of ecological civilization in China. Acta Ecol. Sin. 2016, 36, 6328-6335. [CrossRef]

4. Colwell, R.K.; Brehm, G.; Cardelús, C.L.; Gilman, A.C.; Longino, J.T. Global warming, elevational range shifts, and lowland biotic attrition in the wet tropics. Science 2008, 322, 258-261. [CrossRef] 
5. Li, T.T.; Ma, C.; Guo, Z.Z. RSEI model based long time series ecological quality assessment and analysis of influencing factors in Helan Mountains. J. Ecol. 2021, 40, 1154-1165. [CrossRef]

6. Wang, F.T.; Huang, C.S.; Chen, Z.H.; Bao, K. Distribution, ecological risk assessment, and bioavailability of cadmium in soil from Nansha, Pearl River Delta, China. Int. J. Environ. Res. Public Health 2019, 16, 3637. [CrossRef] [PubMed]

7. Wang, M.X.; Liao, G.K.; Li, Y.L. The relationship between environmental regulation, pollution and corporate environmental responsibility. Int. J. Environ. Res. Public Health 2021, 18, 8018. [CrossRef]

8. Zhu, L.Q.; Xu, L.M. Study on the impact of global change on terrestrial ecosystem. Areal Res. Develop. 2011, 30, 161-164. [CrossRef]

9. Wang, Y.H.; Li, J.Y. Evaluation of coupling and coordination between ecological environment quality and economic development level in contiguous destitute areas. J. Appl. Ecol. 2015, 26, 1519-1530. [CrossRef]

10. Wang, D.S.; Wang, X.L.; Lei, Z.Y. Ecological quality assessment of fuxin based on remote sensing ecological index. Eco. Sci. 2020, 39, 88-94. [CrossRef]

11. Xu, H.Q. Establishment and application of urban remote sensing ecological index. Acta Ecol. Sin. 2013, 33, 7853-7862. [CrossRef]

12. Sun, C.J.; Li, X.M.; Zhang, W.Q.; Chen, W.; Wang, J.R. Assessment of ecological security in poverty-stricken areas of Luliang Mountains based on remote sensing information. Environ. Sci. 2019, 39, 5352-5360. [CrossRef]

13. Ivits, E.; Cherlet, M.; Mehl, W.; Sommer, S. Estimating the ecological status and change of riparian zones in Andalusia assessed by multi-temporal AVHHR datasets. Eco. Ind. 2008, 9, 422-431. [CrossRef]

14. Jiang, C.L.; Wu, L.; Liu, D.; Wang, S.M. Remote sensing dynamic monitoring of eco-environmental quality in arid desert areas: A case study of Gurbantunggut Desert. J. Appl. Ecol. 2019, 30, 877-883. [CrossRef]

15. Wen, L.T. Discussion on remote sensing monitoring of agrometeorological disasters. Remote Sens. 2020, 9, 38-41. [CrossRef]

16. Song, W.; Song, W.; Gu, H.H.; Li, F.P. Progress in the remote sensing monitoring of the ecological environment in mining areas. Int. J. Environ. Res. Public Health. 2020, 17, 1846. [CrossRef]

17. Ministry of Environmental Protection of the People's Republic of China. Technical Code for Assessment of Ecological and Environmental Conditions (In Operation); China Environmental Science Publishing House: Beijing, China, 2006.

18. Ye, Y.H.; Liang, Y.X.; Shen, Y.Q.; Xie, L.S. Some problems to be discussed in technical standard for assessment of ecological and environmental conditions (trial implementation). Trop. Geo. 2009, 29, 404-406. [CrossRef]

19. Liu, H.; Che, G.H.; Gao, C.J.; Zhao, Y.J. Change of ecological environment quality and its influencing factors in Hebei Province. Eco. Sci. 2016, 35, 89-97. [CrossRef]

20. Wang, H.J.; Bi, F.F.; Dong, Z.F. Performance evaluation of ecological compensation policy in Xin Anjiang River Basin based on AHP-fuzzy comprehensive evaluation method. Acta Ecologica Sinica 2020, 40, 7493-7506. [CrossRef]

21. Xu, H.Q. Remote sensing evaluation index of regional ecological environment change. Environ. Sci. 2013, 33, 889-897. [CrossRef]

22. Liao, W.H.; Jiang, W.G. Evaluation of the spatiotemporal variations in the eco-environmental quality in China based on the remote sensing ecological index. Remote Sens. 2020, 12, 2462. [CrossRef]

23. Wang, Y.; Zhao, Y.H.; Wu, J.S. Long-time dynamic monitoring of urban agglomeration ecological quality based on Google Earth Engine Cloud Computing: A case study of Guangdong-HongKong-MacaoGreaterBayArea. Acta Ecol. Sin. 2020, 40, 1-13. [CrossRef]

24. Zhou, L.M.; Wang, S.H. Remote sensing monitoring and assessment of spatial-temporal change of ecological environment in Hang Jin Banner, Inner Mongolia. J. Appl. Ecol. 2020, 31, 1999-2006. [CrossRef]

25. Zhu, D.; Chen, T.; Zhen, N.; Niu, R.Q. Monitoring the effects of open-pit mining on the eco-environment using a moving window-based remote sensing ecological index. Environ. Sci. Pollut. Res. Int. 2020, 27, 15716-15728. [CrossRef]

26. Liu, K.; Ma, N.X.; Xu, Y.L.; Sun, G.N. Protection and construction of ecological environment in Qinling Mountains. Chin. J. Ecol. 2004, 23, 157-160. [CrossRef]

27. Liu, Y.S.; Ni, S.X.; Jiang, J.J. Comprehensive evaluation of ecological environment quality in southern Shaanxi Mountain. Mt. Res. $1997,3,178-182$.

28. Lang, G.D.; Guo, J.L. Study on the ecological environment quality of Taibai Mountain scenic area. J. Northwest Univ. 2001, 5 , 431-433. [CrossRef]

29. Zhang, Y.Q.; Jiang, F.; Ji, M.D.; Jiang, H.S.; Wang, Z.Y. Evaluation of ecological environment at district and county level based on remote sensing index. Arid. Zone Stud. 2020, 37, 1598-1605. [CrossRef]

30. Zhao, F.; Zhang, B.; Zhu, L.; Yao, Y.; Cui, Y.; Liu, J. Spatial differentiation of vertical band spectral structure in Qinling-Daba Mountains and the problem of warm temperate zone-Subtropical boundary. Acta Geogr. Sin. 2019, 74, 889-901. [CrossRef]

31. Zhao, F.; Zhang, J.; Liu, S.; Wang, Z.; Wang, L.; Gu, H.; Li, W. NPP and its response to climate change in Qinling-Daba Mountains: A multi-dimensional zonal and warm temperate-subtropical boundary problem. Acta Ecol. Sin. 2021, 41, 1-12. [CrossRef]

32. Li, Y.H. Research on Multi-Dimensional Changes of Soil Erosion in Qinling-Daba Mountains; Henan University: Kaifeng, China, 2020. [CrossRef]

33. Liu, J.J.; Pan, Z.W.; Qin, F.; Gu, J.Y.; Zhu, M.Y.; Zhao, F. Land temperature estimation and mass elevation effect analysis of Qinling-Daba Mountains based on MODIS data. Geo. Res. 2020, 39, 735-748. [CrossRef]

34. Zhao, Y.L.; Zhang, L.J. Study on quantitative assessment method of fragile ecological environment. Prog. Geogr. 1998, 18, 3-5 [CrossRef] 
35. Goward, S.N.; Xue, Y.K.; Czajkowski, K.P. Evaluating land surface moisture conditions from the remotely sensed temperature /vegetation index measurements: An exploration with the simplified simple biosphere model. Remote Sens. Environ. 2002, 79, 225-242. [CrossRef]

36. Todd, S.W.; Hoffer, R.M. Responses of spectral indices to variations in vegetation cover and soil background. Photogramm. Eng. Remote Sens. 1998, 64, 915-921.

37. Li, B.L.; Jing, C.P.; Yan, X.Y. Derivation of tassel-cap transformation of Landsat 8 land imager image. Sci. Surv. Mapp. 2016, 41, 102-107. [CrossRef]

38. Ashutosh, S.; Roy, P.S. Three decades of nationwide forest cover mapping using indian remote sensing satellite data: A success story of monitoring forests for conservation in india. J. Indian Soc. Remote. Sens. 2021, 49, 61-70. [CrossRef]

39. Xu, H.Q. A new index for delineating built-up land features in satellite imagery. Int. J. Remote Sens. 2008, 29, 4269-4276. [CrossRef]

40. Nichol, J. Remote sensing of urban heat islands by day and night. Photogramm. Eng. Remote Sens. 2005, 71, 613-622. [CrossRef]

41. Ding, F.; Xu, H.Q. Land surface temperature inversion algorithm and experimental analysis of TM thermal band image. J. Geo-informa. Sci. 2006, 8, 125-130, 135. [CrossRef]

42. Chander, G.; Markham, B.L.; Helder, D.L. Summary of current radiometric calibration coefficients for Landsat MSS, TM, ETM+ and EO-1 ALI sensors. Remote Sens. Environ. 2009, 113, 893-903. [CrossRef]

43. Williams, D. Landsat 7 Science Data Users Handbook; U.S. Geological Survey: Sacramento, CA, USA, 1998. [CrossRef]

44. Jimenez-Munoz, J.C.; Cristobal, J.; Sobrino, J.A.; Soria, G.; Ninyerola, M.; Pons, X. Revision of the single-channel algorithm for land surface temperature retrieval from Landsat Thermal-Infrared data. IEEE Trans. Geofence Remote Sens. 2009, 47, 339-349. [CrossRef]

45. Qi, Y.C.; Dong, Y.S.; Jin, Z.; Peng, Q.; Xiao, S.S.; Ya-ting, H.E. Spatial heterogeneity of soil nutrients and respiration in the decertified grasslands of inner mongolia, China. Pedosphere 2010, 20, 655-665. [CrossRef]

46. Wang, M.; Wang, J.; Meng, Z.; Cai, X.; Lv, S.; Wang, D.; Wu, Y. Heterogeneity of spatial distribution of Haloxylon ammo dendron population in the eastern margin of Badain Jaran Desert. Acta Ecol. Sin. 2016, 36, 4055-4063. [CrossRef]

47. Yan, L.; Zhou, G.; Zhang, F.; Sui, X.; Ping, X. Spatial heterogeneity dynamic analysis of vegetation coverage in desert steppe of Inner Mongolia. Acta Ecol. Sin. 2012, 32, 4017-4024. [CrossRef]

48. Wang, J.F.; Xu, C.D. GEO-DETECTOR: Principles and prospects. Acta Geogr. Sin. 2017, 72, 116-134. [CrossRef]

49. Fan, C.; Xia, B.C.; Qin, J.Q. A comprehensive evaluation model of county eco-environmental quality based on RS and GIS: Taking Huidong County as an example. Chin. J. Ecol. 2013, 32, 719-725. [CrossRef]

50. Liu, P.; Ren, C.Y.; Wang, Z.M.; Zhang, B.; Chen, L. Assessment of the eco-environmental quality in the Nanweng River nature reserve, Northeast China by remote sensing. J. Appl. Ecol. 2018, 29, 3347-3356. [CrossRef]

51. Wang, L.C.; Jiao, L.; Lai, F.B.; Zhang, N.M. Ecological change assessment of Manas Lake Wetland in Xinjiang based on remote sensing ecological index. Acta Ecol. Sin. 2019, 39, 2963-2972.

52. Wang, Y.; Wang, S.D. Analysis of dynamic change of ecological quality based on RSEI: A case study of Danjiang River (Henan Section). Sci. Soil Water Conserv. 2019, 17, 57-65. [CrossRef]

53. Gao, W.P.; Alimjiang, k.; Tursunayi, R.; Zhao, M. Spatio-temporal analysis of ecological and environmental benefits in Yizhou District. Arid. Zone Res. 2020, 37, 1057-1067. [CrossRef]

54. Li, F.L.; Chang, Q.R.; Shen, J.; Liu, J. Dynamic monitoring of ecological environment in some random place somewhere region by remote sensing: A case study of Fuxian County, Shaanxi Province. J. Appl. Ecol. 2015, 26, 3811-3817. [CrossRef]

55. Liu, T.; Bao, G.D.; Zhai, C.; Yang, J.; Zhang, D.W.; Lv, M.Y. Change of eco-environmental quality and its driving forces in ecologically fragile areas. Jilin For. Sci. Technol. 2020, 49, 18-25. [CrossRef]

56. Wang, J.; Liu, D.; Ma, J.; Cheng, Y.; Wang, L. Development of a large-scale remote sensing ecological index in arid areas and its application in the Aral Sea Basin. J. Arid Land. 2021, 13, 40-55. [CrossRef]

57. Li, F.M.; Yin, S.Y.; Yin, T.Y. Study on the spatial-temporal variation of extreme temperature in Qinling-Daba mountains and its adjacent regions from 1960 to 2017. Proc. Natl. Sun Yat-Sen Univ. 2020, 272, 86-98. [CrossRef]

58. Zhang, B.P.; Yao, Y.H. Mass Elevation Effect Study; China Environmental Science Publishing House: Beijing, China, $2015 ;$ pp. 45-93.

59. Cong, N.; Shen, M.; Yang, W.; Yang, Z.; Zhang, G.; Piao, S. Varying responses of vegetation activity to climate changes on the Tibetan Plateau grassland. Int. J. Biometeorol. 2017, 61, 1433-1444. [CrossRef] [PubMed]

60. Zhang, B.P. Ten scientific problems in the study of the north-south transition zone in China. Progr. Geogr. 2019, 38, 305-311. [CrossRef]

61. Yang, J.; Wu, T.; Pan, X.; Du, H.; Li, J.; Men, M.; Chen, Y. Ecological quality assessment of Xiongan New Area based on remote sensing ecological index. J. Appl. Ecol. 2019, 30, 277-284. [CrossRef]

62. Zhu, Q.; Guo, J.; Guo, X.; Xu, Z.; Ding, H.; Han, Y. Spatial differentiation of eco-environmental quality and its influencing factors in Poyang Lake region. J. Appl. Ecol. 2019, 30, 4108-4116. [CrossRef]

63. Li, J.; Feng, X.; Yin, J.; Chen, F. Change analysis of spring vegetation green-up date in Qinba Mountains under the support of spatiotemporal data cube. J. Sens. 2020, 3, 1-12. [CrossRef]

64. Jia, L.; Liu, Y.; Liu, J.; Li, J. Analysis on the causes of poverty in China's contiguous extreme poverty-stricken areas and its helping needs. Hum. Geogr. 2018, 33, 85-93. [CrossRef]

65. Ren, Q.R. Coupling analysis of coordinated development of eco-environment and socio-economic system in Gansu Province. J. Ecol. 2021, 41, 2944-2953. [CrossRef] 
66. Zhu, W.; Zhang, J.; Cui, Y.; Zhu, L. Ecosystem carbon storage under different scenarios of land use change in Qihe catchment, China. J. Geogr. Sci. 2020, 30, 1507-1522. [CrossRef]

67. Zhang, J.; Zhu, W.; Zhu, L.; Cui, Y.; He, S.; Ren, H. Topographical relief characteristics and its impact on population and economy: A case study of the mountainous area in western Henan, China. J. Geo. Sci. 2019, 29, 598-612. [CrossRef]

68. Yin, H.; Zhang, P.; Dong, Q.; Chen, Q.; Zhu, L. Evaluation on climate comfortable degree for ecotourism along altitude gradient in Qinling-Daba Mountains areas, China. J. Mt. Sci. 2021, 39, 710-721. [CrossRef]

69. Schmidt, D.N. Determining climate change impacts on ecosystems: The role of palaeontology. Palaeontology 2018, 61, 1-12. [CrossRef]

70. Wang, L.; Chen, S.; Zhu, W.; Ren, H.; Zhang, L.; Zhu, L. Spatiotemporal variations of extreme precipitation and its potential driving factors in China's North-South Transition Zone during 1960-2017. Atmos. Res. 2021, 252, 105429. [CrossRef] 